\title{
Quantitative Analysis of Drag Reduction Methods for Blunt Shaped Automobiles
}

\author{
Ferenc Szodrai 1 \\ Department of Building Services and Building Engineering, Faculty of Engineering, University of Debrecen, \\ 4028 Debrecen, Hungary; szodrai@eng.unideb.hu
}

Received: 30 April 2020; Accepted: 19 June 2020; Published: 23 June 2020

\begin{abstract}
In fluid mechanics, drag related problems aim to reduce fuel consumption. This paper is intended to provide guidance for drag reduction applications on cars. The review covers papers from the beginning of 2000 to April 2020 related to drag reduction research for ground vehicles. Research papers were collected from the library of Science Direct, Web of Science, and Multidisciplinary Digital Publishing Institute (MDPI). Achieved drag reductions of each research paper was collected and evaluated. The assessed research papers attained their results by wind tunnel measurements or calculating validated numerical models. The study mainly focuses on hatchback and notchback shaped ground vehicle drag reduction methods, such as active and passive systems. Quantitative analysis was made for the drag reduction methods where relative and absolute drag changes were used for evaluations.
\end{abstract}

Keywords: active flow control; passive flow control; coefficient of drag; ground vehicle; car

\section{Introduction}

In the field of fluid mechanics, drag related problems are fascinating to examine. With a small modification of complex geometry, flow aerodynamics can be changed; thus, less energy will be needed for the propulsion system for a vehicle.

Drag related problems were first examined in the aeronautical industry after the automotive industry also realised that it could affect fuel consumption reduction. For ground vehicles, drag related problems are specific due to external effects, such as road inclination and wind. However, the examined velocity regime is tighter than the airplanes because the speed is limited to $50-130 \mathrm{~km} \mathrm{~h}^{-1}$. This limit also gives us several more simplifications, as the air can be incompressible and isothermal due to low velocity. In addition, road vehicles suffer more from pressure drag compared to airplanes and ships, where skin friction is more relevant.

Ground vehicles have many small additions attached to their surfaces, e.g., mirrors, sunroof, antennas. These small shapes are not intended to have large impacts on aerodynamics and fuel consumption, yet could generate some noise [1]. Small objects (e.g. wings, winglets, flaps) on the surface of the vehicles can be categorized as vortex generators (VGs). Firstly, the VG was introduced by Taylor [2] in 1950. It had two purposes: delay flow separations and increase pressure inside the wake region for aircraft wings. With these properties, regardless of creating some drag locally, the overall altered pressure distribution could reduce the total drag coefficient $\left(C_{D}\right)$. Similarly, special active devices or shape modifications could also alter flow around vehicles to reduce drag.

Studies related to drag reduction and vortex generators were made recently. For example, examining the connection between heat transfer and VGs by Chai et al. [3] and, also, topology optimization in the field of fluid mechanics by Alexandersen et al. [4]. Notable reviews connected to road vehicles and drag were made in 1993 [5], continued by a review in 2014 for heavy vehicles [6]. 
This review covers papers from the beginning of 2000 to April 2020, intended to provide a guidance for drag reduction method application on ground vehicles. Thus, the quantitative analysis mainly focuses on research results between 2008 and 2020. The assessed research papers attained their results by wind tunnel measurements or calculating validated numerical models. The study mainly focuses on hatchback and notchback shaped ground vehicle drag reduction methods, such as active and passive systems. The presented results could be applied to ground vehicles below subsonic regions where air density is considered constant; thus, methods can be applied for low tip speed wind turbines. Nonetheless, lift coefficients are not discussed. In addition to the previous reviews, this work provides a detailed quantifiable comparison between drag reduction methods.

\section{Layout of Paper}

The included papers are divided into different subcategories, based on drag reduction methods. The layout of this paper is also divided into different sections. The literature review is presented in Section 2, where, firstly, it discusses the drag calculation in Section 2.1; secondly, discusses the major vehicle shapes in Section 2.2; thirdly, gives a closer look at the possible solutions in Section 2.3. A quantitative comparison was made in Section 3. Finally, recommendations made for future works are found in Section 4.

\section{Literature Review}

In order to collect relevant amounts of information for this review, research and review papers were looked up in the database of Science Direct, Multidisciplinary Digital Publishing Institute (MDPI), and also in the Web of Science, between the beginning of 2000 and April 2020.

The applied keyword combinations were drag, drag reduction, vortex generator, vehicle, ground vehicle. In addition to the above, reverse tracking was used as a reference for the pivotal papers in the area, as well as relevant references in the papers from the research. Only journal publications were included, except where important contributions were made from the available conference proceedings. Literature that examined the relationship between VGs and thermal reaction, flows above supersonic velocities, and underwater drag related problems were excluded from the analysis. Other fuel saving methods for ground vehicles that had no connection to aerodynamic drag were also eliminated. Few additional exceptions were made in regard of drag reduction, where its effect was examined in isolated subsonic scenarios. Figures from the research papers are not presented intentionally, yet, summarized illustrations are made based on their findings.

The main objective of this study is to answer the following questions:

- What typical flow structures are created around a vehicle?

- What methods were used to reduce drag in the past decade?

- From the available methods, can active systems, shape, or topology optimization be a viable solution to reduce drag?

- What are the drag reduction capability limits for different methods?

\subsection{Aerodynamic Drag}

When an object is placed in a flow, or when an object is moving in fluid, forces are applied to its surface. Former cases are referred to analytical measurements while latter is a real-life approach. These two cases could be compared and gives us similar results with adequate restrictions. These forces, due to shear stress, try to decrease speed of movement; thus, energy is dissipated. This kinetic energy loss is converted to heat energy. The dissipation rate is amplified at high velocities above subsonic level. In those cases, examined fluid regions cannot be considered incompressible and isothermal. Due to regional speed limit regulations, ground vehicles are far from the speed of sound. For that reason, it is possible to consider the air isothermal and incompressible. 
In Figure 1, an object is immersed in air flow and the affected forces can be seen. In front of the body (indicated with red) pressure drag is created, which is one of the crucial aerodynamic losses that can occur on a body. On the sides (indicated with green), skin friction losses could only cause minor drag. Magnitude can be amplified if complex geometry creates flow separation. Similarly, to the frontal, side force is applied on the body to the direction of the flow on the rear (indicated with blue). The flow also creates drag and lower pressure to the ambient pressure. Thus, it can be called negative pressure zone, or wake region, in attribute to its highly turbulent behaviour, where vortex shedding and recirculation bubbles could appear. In Ahmed et al. [7], it was concluded that the rear end flow has more impact on the drag than on the frontal side.

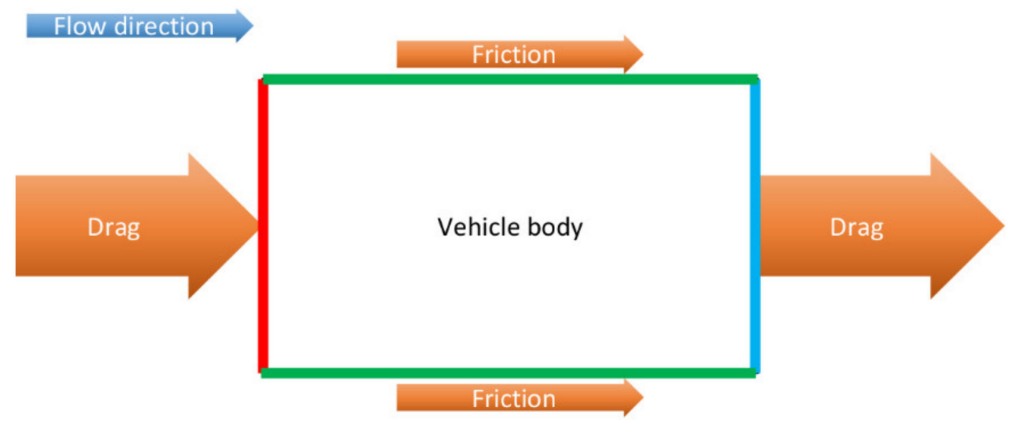

Figure 1. Forces on a vehicle body in a flow.

The drag force coefficient $\left(C_{D}\right)$ is the function of the drag force $\left(F_{D}\right)$ acted on the vehicle surface; $\rho$ and $\mathrm{v}$ are the density and the flow velocity, respectively. A is the projection area of the vehicle, in the direction of the movement.

$$
\mathrm{C}_{\mathrm{D}}=\mathrm{F}_{\mathrm{D}} \cdot\left(0.5 \cdot \rho \cdot \mathrm{v}^{2} \cdot \mathrm{A}\right)^{-1}
$$

$\mathrm{C}_{\mathrm{D}}$ considered to be a quasi-constant value. However, Gil [8] shows that at lower velocities $\left(15 \mathrm{~m} \mathrm{~s}^{-1}\right)$, it does not have linear connection with $F_{D}$. Furthermore, $C_{D}$ should be a time averaged value, due to vortex shedding. Drag force can be experimentally determined in wind tunnels where the body is attached to a force sensor. If full-scale measurement cannot be performed in wind tunnels, small-scale measurements can be made. A smaller scale with the combination of a low-Reynolds (Re) number could make the force sensor inadequate for $\mathrm{F}_{\mathrm{D}}$ measurements. Barros et al. [9] concluded that the $\operatorname{Re}=3 \times 10^{5}$ leads to a $2 \%$ overall difference in the drag coefficient. Gil [8] reported 1.7\% uncertainty in his work. $C_{D}$ measurement accuracy can be increased to $0.05 \%$ [10]. The drag reduction is often measured in Count, which is equal to $0.001 C_{D}$ change compared to the initial. For example, if a vehicle with $C_{D}=0.3$ measured with a method that has $0.05 \%$ inaccuracy, the drag reduction below 0.15 Counts just as a measurement error.

Götz [11] has published a more detailed method to calculate wind average drag coefficient for on-road measurements where the road inclination, wind speed magnitude, and direction were included. However, in the examined studies, $C_{D}$ is simplified since vehicles are examined in wind tunnels and numerical models. Barden et al. [12] made on-road measurements with logged external parameters where vehicle speed fuel consumption and drag estimation were also measured; these are precise values. However, for design period, it is not possible, which is why it is essential to know what method leads to greater drag reduction.

For this paper, an important parameter is the drag reduction (DR), which is the percentile reduction of the initial. $C_{D}$ is calculated by the following:

$$
\mathrm{DR}=100 \% \cdot\left(\mathrm{C}_{\text {Dinitial }}-\mathrm{C}_{\mathrm{D} \text { reduced }}\right) \mathrm{C}_{\mathrm{D} \text { initial }}{ }^{-1}
$$


For drag reduction evaluation, Count should be used for aerodynamic (low $C_{D}$ ) vehicles and DR for blunt vehicles (high $\mathrm{C}_{\mathrm{D}}$ ). This application change can be visualized more easily, since with count, small changes are amplified, while with DR, values are normalised.

\subsubsection{Particle Image Velocimetry}

To examine negative pressure zones, there are two preferred methods: wind tunnels and computational fluid dynamics (CFD). In wind tunnels, by injecting smoke in front of the examination zone, flow can be examined. Particle Image Velocimetry (PIV) is a more advanced version of this method where the measured particles in the air are digitalized in a way that velocity can be calculated. The PIV system consists of a laser (which highlights small intentionally added particles in the flow), a camera, and software, which helps to observe the turbulent flow. In the turbulent flow, velocity distribution and wake formation can be examined [13]. With this method, drag cannot be calculated. For drag calculation, force sensors are required, which will be able to determine the $\mathrm{F}_{\mathrm{D}}$ change on the entire examined body. There are cases $[14,15]$ when pressure sensor arrays are placed on the rear surfaces of the vehicles, yet only partial drag reduction can be mentioned.

\subsubsection{Numerical Models}

Numerical (CFD) models intended to predict flow in a computational domain with the combination of Navier-Stokes equations and turbulence prediction techniques. Nowadays, three main methods used: large eddy simulation (LES), detached eddy simulation (DES), and Reynolds Averaged Navier-Stokes (RANS) equations. For drag related problems, on one geometry, LES can use [16] to compare results with PIV [17]. For optimization where numerous geometries are examined, steady state RANS simulations are preferred due to low computational demands. However, $C_{D}$ in most of the cases has to be calculated over time, in attribute to vortex fluctuations, as Yong et al. [18] shows. Steady state modelling can only be used when deviations are in an acceptable range. Utilizing the advantage of both methods, DES can be applied. The purpose of this method is that it only calculates with LES where vortex shedding occurs, while the rest is calculated with RANS. With DES, vortex shedding can be examined with relative less computational time [19]. RANS method is simple, yet in valid cases, it could show, as precise values as attained with LES [20,21].

PIV and CFD methods should be bounded strongly together to compare flows. Simulations carried out by the RANS method should be compared with PIV to ensure accurate predictions.

\subsection{Vehicle Shapes}

Ground vehicles have different types of shape. Their shapes, in most cases, are not designed to have good aerodynamic properties, such as light trucks, buses, lorries, freight trains. These were designed to have large volumes, which lead to bluff shape. The other side of this concept are vehicles that are made purposely to have as low drag as possible, such as race cars and motorbikes where carrying capacity is irrelevant. All of these vehicles have three-dimensional (3D) complex geometries with small details, when drag related problems, the aim is to examine the effect of these small changes. Vehicles have vast amount of shapes and even the categorization could be difficult, thanks to the overlapping categories. To oversimplify vehicle shapes, regardless of size notchback, hatchback shapes can be defined from the drag related problem point of view. These two were chosen since they have strong similarities to commercially available cars and heavy trucks.

\subsubsection{Hatchback}

Hatchback is a simple box shaped vehicle often referred as bluff or blunt bodied (see Figure 2), where the total height of the wake region is equal (or even larger [22], see Figure 2a) to the height of the vehicle, which was visualized by Boyer et al. [23] for a pickup truck. 


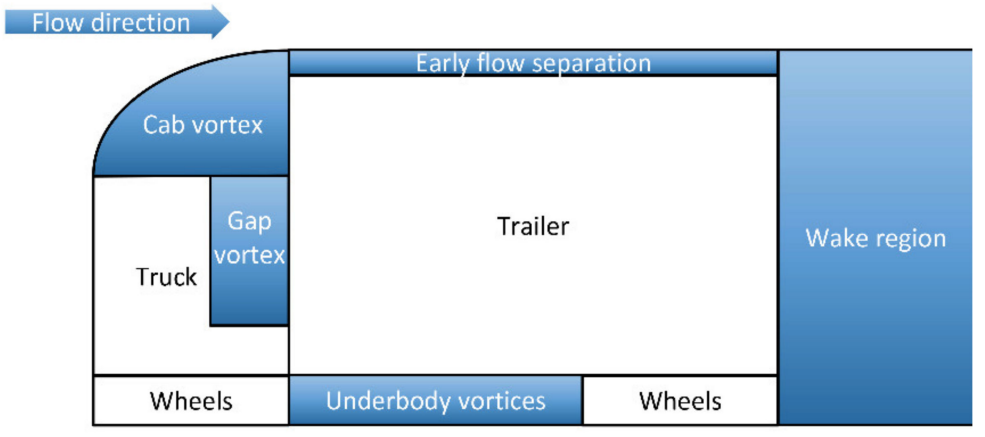

(a)

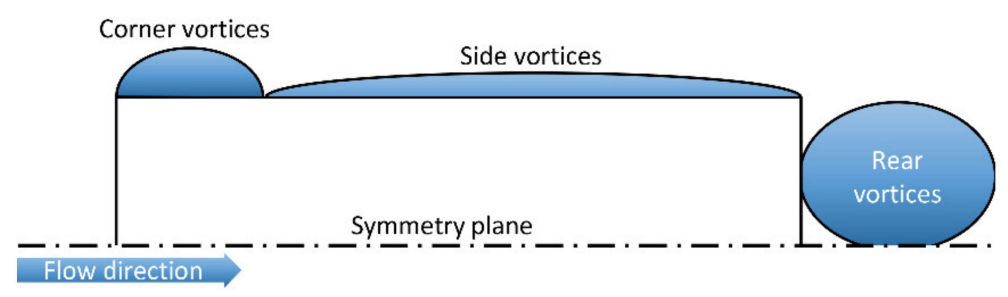

(b)

Figure 2. Side (a) and top (b) view of a heavy truck (based on $[16,23])$.

Heavy trucks usually have a bluff shape with large wake regions; in Figure 2, the wake regions are indicated with blue. These wake region sizes vary due to external effects (e.g. crosswind, vortex shedding); flow fluctuation can be asymmetrical or periodic. Yet at a certain velocity, the time averaged size could be considered constant. When aerodynamic enhancement is made, the aim can be to reduce the size of the blue zone.

Bluffness also causes instability problems in crosswind scenarios, as McArthor et al. [24] stated. Giappino et al. [25] have made experimental and numerical investigations into the relationship of the cross wind affecting the container wagons, and their drag related problems.

Long vehicles, such as lorries in crosswind, could have instability problems due to drag; even at higher yaw angles, von Kármán vortex could also be observed [24]. Later, it was supported by Rao et al. [16], where they investigated heavy trucks with large eddy simulations (LES). They observed two notable wake regions: one at the corner vortices (see Figure 2b), which originate from either side of the vehicle, and one at the back. The size of the corner vortices was considerably deformed when the yaw changed $2.5^{\circ}-10^{\circ}$. The instability with CFD or with PIV can be highlighted by examining the symmetry or the wake region; if the asymmetry of the wake regions increasing, instability could occur. A symmetric scenario can be seen in Figure $2 b$, and the asymmetric scenario is detailed by Rao et al. [16]. In addition, Boyer et al. [23] showed that flow separation occurs over the hood of these vehicles.

Further wind tunnel measurements were made for the well-defined and simplified geometries, such as the Windsor body [26], Asmo body [27-29], or Ahmed body without rear slant [9].

The Windsor model is a well-specified car geometry [30,31], where $2 \%$ accuracy validated numerical models were examined. Luckhurstet et al. [31] concluded that with slight modifications, it could reduce the drag by 4 Counts, which could be expressed by $0.5 \mathrm{CO}_{2} \mathrm{~g} \cdot \mathrm{km}^{-1}$ or $2 \mathrm{~km}$ additional distance for an electric vehicle. 


\subsubsection{Notchback}

Notchback types are similar to hatchbacks. The best presentation of this shape is the Ahmed body [7], which is a highly utilized car geometry, both in CFD models [32] and in wind tunnels [33,34]. The altered version of this model is often used for drag-related researches. The main difference is rear slant, as can be seen in Figure 3. This slant could reduce the wake region behind the vehicle; in addition, that slant flow separation could occur.

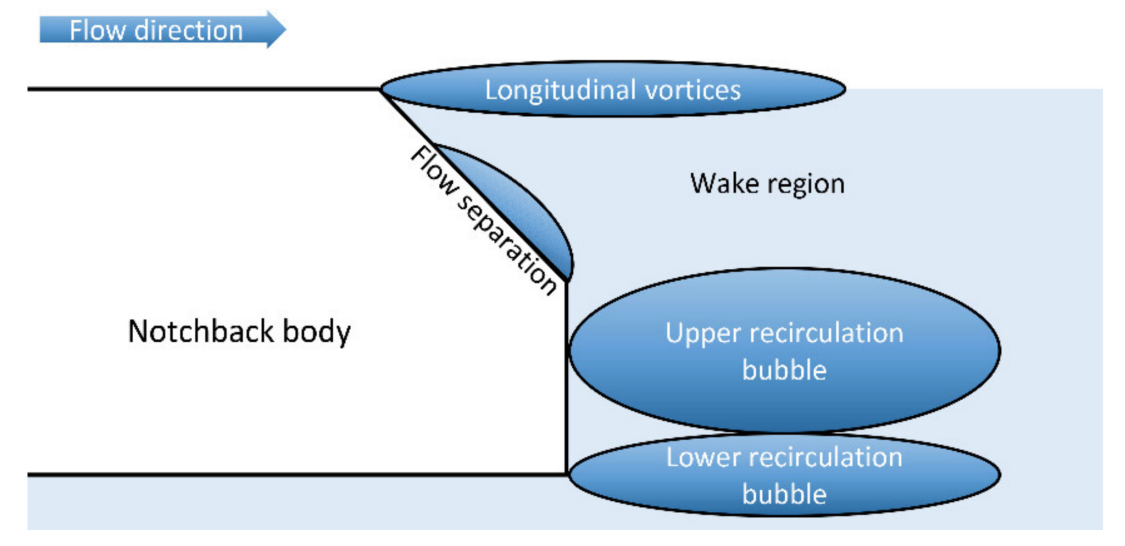

Figure 3. Generated vortices behind a notchback vehicle (based on Zhang et al. [35]).

Behind any type of vehicle, two recirculation bubbles occur: the upper one is caused by the flow above the vehicle and the bottom one is from under. The lower one is usually smaller than the upper one. The combination of these causes the flows at the sharp edges, along the flow longitudinal vortices generated, as was concluded in Zhang et al. [35]. By shrinking these recirculation bubbles at a given velocity, the negative pressure difference can be reduced; thus, $C_{D}$ reduced.

Newer, well defined geometries also appear with the likes of the DrivAer [36-39] model. With a more detailed geometry, more realistic cases can be examined; yet, the generalization of the phenomenon could be difficult since car shapes change over time. Other vehicle geometries were also examined in the papers, yet those are used for specific research.

\subsection{Aerodynamic Drag Reduction}

Drag can change in certain velocity regimes or in crosswind scenarios [37]. Reducing the vehicle drag coefficient can be done by modifying its shape or applying active or passive flow control systems. Even with controlled movement, platooning drag and fuel consumption reduction can be achieved, as Boysen et al. [40] and Jacuzzi et al. [41] evaluated from numerical models. The increase of autonomous vehicle research could have great potential to reduce drag [42-44]. At the design stage, low $C_{D}$ vehicle can be created by modelling a shape that can be found in nature, just like the one in Chowdhury et al. [45]'s work.

\subsubsection{Active Systems}

For active systems to operate, power is required, which has to be less than the reduced propulsion demand to be effective. An active system can reduce the drag with different methods, but in most cases, it is injecting steady or pulsating flow in the rear wake region, even with wheel-vehicle interaction drag can be reduced, as Wang et al. [29] showed on an Asmo model. For steady jet flow (SJF), active drag reducing systems flow can be transferred from the frontal high-pressure zone [46]. SJF systems were used in works by Pastoor et al. [47], Aubrun et al. [48], Littlewood et al. [49], and Zhang et al. [15], where these were placed in an array [47-49] or along the trailing edges $[15,47,50]$. These methods simply reduced the pressure difference at the rear end. With higher flowrate (and more jets), larger DR was achieved. In work by Hui et al. [10], high frequency $(f=6.7 \mathrm{kHz})$ plasma flow was induced. 
In their findings, it was concluded that at higher velocities the magnitude of the drag reduction was decreased, peak DR was achieved at $10 \mathrm{~m} \mathrm{~s}^{-1}$.

For pulsating flow generation, synthetic jet actuators (SJA) are used, these are low frequency flow control systems where a membrane generates a periodic minimal flow, which increases or decreases the Kelvin-Helmholtz instability effect [51]. For flow actuations, Strouhal number (St) is used in some analysis

$$
\mathrm{St}=\mathrm{f} \cdot \mathrm{H} \cdot \mathrm{v}^{-1}
$$

where $\mathrm{H}$ is the height of the vehicle. On a simplified (bullet) shape, Gil [8] showed that SJA systems has some uncertainties. $C_{D}$ was constant above $10 \mathrm{~m} \mathrm{~s}^{-1}$, when the velocity decreased from this value $\mathrm{C}_{\mathrm{D}}$ increased, in addition, when SJA was used, $\mathrm{DR}=6 \%$ and $\mathrm{DR}=-22 \%$ were achieved. This high fluctuation reduced at higher velocities along with the maximum DR. This peak DR as corresponded to $\mathrm{St}=0.25$, which was close to its natural shedding frequency [47]. On a similar D-shape, Gao et al. [52] also concluded that the peak DR was close to this shedding frequency $(\mathrm{St}=0.2)$. Gilléron et al. [53] found a peak DR in $0-550 \mathrm{~Hz}$ frequency range $\left(\mathrm{f}=500 \mathrm{~Hz} ; \mathrm{H}=0.202 \mathrm{~m} ; \mathrm{v}=30 \mathrm{~m} \mathrm{~s}^{-1}\right)$ this was at $\mathrm{St}=$ 3.6. This value is close to findings by Kourta et al. [14], yet the magnitude of DR was less. They also concluded that $\mathrm{St}$ has less significance and Re has stronger connection to DR. Close to this DR, on a comparable shape (Ahmed body), Tounsi et al. [51] results peaked at $\mathrm{St}=5.84$. The SJA system flow direction was normal to the main flow.

For on-road measurements, where the velocity is highly fluctuating, adaptive controlling is required [47,54]. Barros et al. [9], on a square back version of an Ahmed body, induced flow parallel to the top surface with high frequency St $=12.1$, this DR was close to Gilléron et al. [53] 18\% and $20 \%$, respectively.

These experiments are done with PIV, for the active method numerical analysis is rare [55-57]. Low amounts can be due to the fact that the validation measurement already has enough information. There are promising projects that show new ideas and applications of active systems on other car geometries. For numerical modelling, Bruneau et al. [57] used a combination of jet actuations and porous top layer on a Ahmed body; a remarkable DR $=31 \%$ was presented.

Active systems can be used at higher velocities effectively when an active grille shutter control mechanism is used [58], or can supply other active DR systems when a small turbine is applied in the vehicle [59]. The advantage is that the utilized power is proportional to the speed. In an urban environment, where accelerating and braking are more frequent for electric vehicles, it could also help to power these systems [60].

\subsubsection{Shape Optimization}

Shape optimization is a highly researched field, both in the field of fluid mechanics and other fields of the automotive industry $[4,61,62]$. While active system jets create vortices, on passive systems a modified shape can create or reduce the wake region. The simplest shape optimization method for drag reduction is when the wake regions are covered with fairings. At the frontal edge of the vehicle, corner vortices could appear typically at blunt shapes, especially for light trucks on the top side, where vortex shedding could occur, though on most vehicles, vortex separation occurs at the rear end.

Gunpinar et al. [63] carried out 1000 two-dimensional numerical simulations for shape optimizations. Their work showed a $6 \%$ difference between measurements, the lowest $C_{D}$ was 0.186 and the highest was 0.556 .

For heavy trucks, the major wake regions (see Figure 2) are the upper cab, between the trailer wheels and rear end regions. Drag created by the wheels in the wake region could be reduced by using only flap-type side skirts for heavy trucks in the work of Hwang et al. [17]. This reduction was $5.3 \%$ while the difference between the experiment and numerical model was $3.7 \%$. For the rear end, boat tails can be applied, as work by Lee et al. [64] and Lorite-Díez et al. [65] shows. By mimicking a seal face on a truck cab, DR $=22.5 \%$ was concluded [66]. By covering the gap between the truck and trailer, DR $=16.4 \%$ was evaluated by Kim et al. [67]. Peng et al. [68] stated that the frontal aerodynamic 
enhancement influenced the rear end wake region. In work by Kim et al. [69], where side skirts and boat tails were applied, the DR decrease led to an estimated 13.4\% fuel saving. Chowdhury et al. [22] have examined various shapes of trucks used in the Indian subcontinent (typically large $C_{D}$ vehicles) that generate large wake regions above and behind the vehicle. By using fairings compared to the baseline construction, the $C_{D}$ was reduced by $12 \%$. The other constructions showed that the generated wake zone that highly reduces the DR can be as low as $14-22 \%$ compared to the base line model. This proves that the vortices on the top side could have negative effects.

To reduce the lower recirculation bubble, "rear under-body slice" shape optimization was carried out by Rakibul Hassan et al. [70]. Vignesh et al. [71] have shown that, with only hood inclination change, the drag could be reduced considerably.

When Ahmed body was tested for the first time by Ahmed et al. [7] in 1984, a shape optimization was made by examining the flows at different slant angles. In that paper, it was concluded that the lowest $C_{D}$ was at $10^{\circ}$ slant angle. Much later, in 2018, with adjoint shape optimization, the base pressure was increased at the rear end of the vehicle. This method validated ( $0.6 \%$ difference) that the drag was reduced by $12.1 \%$ in the work by He et al. [72].

In smaller vehicles, such as the Windsor body, by changing the pitch angle by $1^{\circ}$, Pavia et al. [30] reduced the $C_{D}$ by $4.9 \%$, showing high sensitivity to the DR. With a rear tapered shape of the Windsor body, Howell et al. carried out around DR $=10 \%$.

On bluff bodies, numerical models could show large DR, such as DR $=50 \%$ in the works of Hassan et al. [73], Holt et al. [74], and Chandrashekhar et al. [75]; however, the results have to be treated carefully since experimental validation is required.

For the advanced shape optimization method, Liu et al. [76] used shape-adjustable quadrilateral surfaces for optimization. This work emphasizes and describes the optimization method, yet results have not been validated by experimental measurements.

\subsubsection{Topology Modification}

When an additional object is placed on the vehicle, its topology is modified. This modification could alter the flow around the body. These objects can be categorized into smaller categories, such as winglets, wings, flaps, spoilers, and splitter plates. If these modifications could generate longitudinal vortices or delay flow separation, it can be categorized to VG. In more specific terms, VG is a small surface that alters a flow along a larger surface.

As it was mentioned, VG has advantageous properties in heat transfer as the vortices modifies the temperature and velocity distributions [3]. In the automotive industry, VG is applied to reduce the wake regions behind the vehicle. Salati et al. [77] examined VG with both numerical models and wind tunnel tests. Its advantageous effects, besides drag reduction, were that they have found that it also reduces the overturning risk, slightly. Firstly, VG DR effect is presented by its individual vortex size reduction side and, secondly, when these are applied on vehicles.

VG could have different types of shapes (see Figure 4); delta and rectangular shapes are the most well-known. If the connecting VG edge is perpendicular to the flow, it is categorized to wings (see Figure 4a), and when it is parallel, winglets (see Figure 4b). There is also a third case when it is attached to the edge of the vehicle, these are known as flaps (see Figure 4c). 


\section{Flow direction}

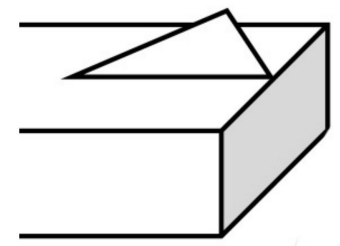

(a)

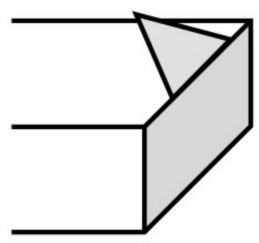

(b)

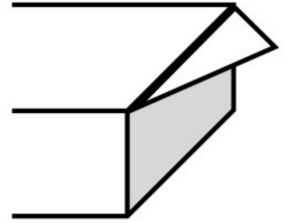

(c)

Figure 4. Delta shaped vortex generator types winglet (a); wing (b); flap (c) (based on $[3,78,79])$.

The offset between two delta shaped winglets was examined in the work by Li et al. [80]. They concluded that the maximum drag reduction was achieved at 5 offset distance/VG height ratio. This study was made for wind turbines, although, thanks to the subsonic velocity regime, it could also be applied to ground vehicles. In their other [81] work, they studied the height and boundary layer ratio for wind turbines. The requirements and goals were different, but they concluded that the drag was reduced by the most (84.9-83.2\%) when the height of the VG height was between the $66-100 \%$ of the total height of the boundary layer, while the installation angle did not affect the $C_{D}$ [82]. Rectangular, triangular, and symmetrical NACA0012 shaped VG were examined on a flat plat in the work of Gutierrez-Amo et al. [83]. In their work, they presented that the shape had strong connection to the vortex size generated after the VG. Streamlined shapes had smaller vortex sizes than rectangular ones. The effects on winglets under adverse pressure gradient, numerically, was looked at by Errasti et al. [84]; in their experiment, the VG was placed on a ramp. For flat plate examinations, the drag coefficient cannot be concluded; therefore, other values should be examined, such as the wall shear stress. This value can predict the flow separation, as Godard et al. $[85,86]$ concluded. It was shown that VG can be modelled by simple Reynolds-Averaged Navier-Stokes (RANS) turbulence models. With the combination of polyhedral mesh and $\mathrm{k}-\omega \mathrm{SST}$, and Spalart-Allmaras turbulence models, good convergence was concluded [87].

There is no accepted unified height for the VG; however, it has a strong connection with the boundary layer where the equipment is applied. Two sizes of VGs were installed at two different locations on a heavy truck by Lo et al. [88]. It was concluded that VG scaled up to $150 \%$, reduced the wake area by about $3 \%$. VGs at the front end were considerably effective in point of wake size reduction $(10.7 \%-12.19 \%$ compared to $2.8 \%-5.8 \%) ; C_{D}$ was not calculated in that work. Shivam et al. [89] concluded that the VG optimal height is the boundary layer height. The VG was placed to delay the flow separation, and for that reason, it was moved to the trailing edge. At 0.6 height of the boundary layer, the wall shear stress peaks, and the value reduces when this value changes, as Ibarra-Udaeta et al. [90] stated. The boundary layer height, even for one vehicle, is constantly changing with the velocity and the wind. To solve this constantly changing parameter question, on a modified Ahmed body (curved rear part) Aider et al. [91] attained DR $=12 \%$ with adjustable/motorized trapezoid shaped VGs. With his solution, the VG height question is solved for dynamic conditions, yet the optimal height, and the on-road boundary layer calculation method, still can be searched.

For VG shape, the delta geometry was favoured in the work of Hasan Ali et al. [92] over the bump shape. With a two-dimensional (2D) model, a sport utility vehicle (SUV) geometry was examined by Sardana et al. [93]. In their work, a delta shaped VG was placed on the top end of the vehicle. They concluded that when VG effect increased the velocity by $7.14 \mathrm{~m} \mathrm{~s}^{-1}$, it reduced the $C_{D}$ by $10 \%$. However, it has to be noted that for further conclusions, 3D and transient modelling is required. Selvaraju et al. [94] showed that delta shaped VGs at the top end of the SUV vehicle could reduce $C_{D}$ by $9.04 \%$. It was also highlighted that, with the increase of velocity, the VG effects are enhanced. 
Sen et al. [95] examined different shapes of VGs. They estimated that when simulated values were compared to measurements ( $27 \%$ difference), it can be concluded that rectangular and triangular shapes are effective DR devices on notchback type vehicles.

VG can be "simple flaps", as in Fourrié et al. [96]'s work, it was applied at the rear end of an Ahmed body, and on the side of the slant in the work by Tian et al. [97]. Altaf et al. [78] examined different elliptic, rectangular, triangular shape flaps on a hatchback vehicle. Their work's main advantage is that three surfaces of the boat tail can be disregarded. They also examined the effect of a perforated surface; however, it did not show favourable results.

Gilliéron et al. [98] used a vertical splitter plate at the rear and front of an Ahmed body. Between the splitter plate and the vehicle wake region formed. The plate distance and height ratio were 0.9 in the favoured case; this was the highest examined ratio, which raises the question: do higher ratios increase DR or not? PIV measurements showed that in front of the plate the wake region almost disappeared. Between the splitter plate and the vehicle, the lower recirculation bubble was more dominant.

Spoilers have similar effect as VGs, as Lee et al. [19] and Bansal et al. [79] have presented; with validated numerical modelling, $C_{D}$ was reduced by $3.1 \%$ and $4.35 \%$, respectively. With a combination of VG and a spoiler, further DR can be done, as Cihan [99] concluded. This leads to $6-12 \%$ fuel reduction, which is about the half of the DR.

Small scale experiments should be evaluated carefully to match these numbers. Velocity has to be low; thus, increasing the risk of von Karman VG could compromise the results. At low velocity $\mathrm{DR}=90 \%$ was achieved in the work by Gopal et al. [100].

\section{Quantitative Analysis}

A quantitative study was made for the evaluation of the referenced methods. During the literature search, 417 papers were screened, and 100 papers were mentioned in the study for analysis. Moreover, 32 research papers had relevant validated results between the beginning of 2008 and April 2020. The low number can be attributed to the over-specified research area. Most drag related problems discussed VG at supersonic velocity regime or for thermal related tasks.

For drag reduction analysis, the active shape and topology categories are divided into subcategories, such as SJA and SJF for active, Fairing (and side skirts) for shape, and topology drag reduction methods for Flap and Winglet. There was a sixth subcategory; those that were not in the first five subcategories due to their uniqueness were categorized as "other" subcategory. For the analysis, initial drag coefficient $\left(\mathrm{C}_{\text {Dinitial }}\right)$, drag reduction (DR), and Count were used. Initial drag coefficients were presented in a boxplot (see Figure 5), where values ranged from 0.08 [19] to 0.98 [47], and the median value was 0.35 . Minimum and maximum values were peaking values, most of them clustered to the $C_{\text {Dinitial }}$ mean value, which was 0.44 with \pm 0.21 standard deviation.

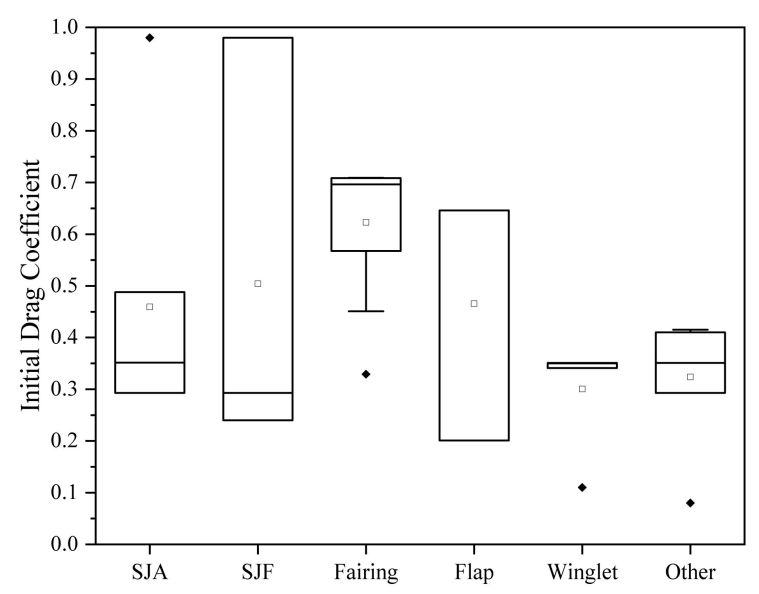

Figure 5. Initial drag coefficient boxplot; (line is median, $\square$ mean, $\downarrow$ peaking values, synthetic jet actuators (SJA), steady jet flow (SJF),). 
For SJF, only three methods were used, that is why was the quartile range was so large. SJA Fairings, Winglets, and other subcategories had peaking values. Similar magnitudes were not found during the literature research. The purpose of Figure 5 is to visualize the initial $C_{D}$ of the vehicle to help further evaluations. DR and Count comparison were made separately since the linear regression $\left(R^{2}\right)$ of the value connection was weak $\left(R^{2}=0.26\right)$. This connection can be seen on Figure 6. Percentile change (DR) evaluation can be more effective with high $\mathrm{C}_{\text {Dinitial }}$ bluff vehicles, while aerodynamic vehicle Count could show some slight differences. Values that were above the regression line were above the mean $\mathrm{C}_{\text {Dinitial }}$ value.

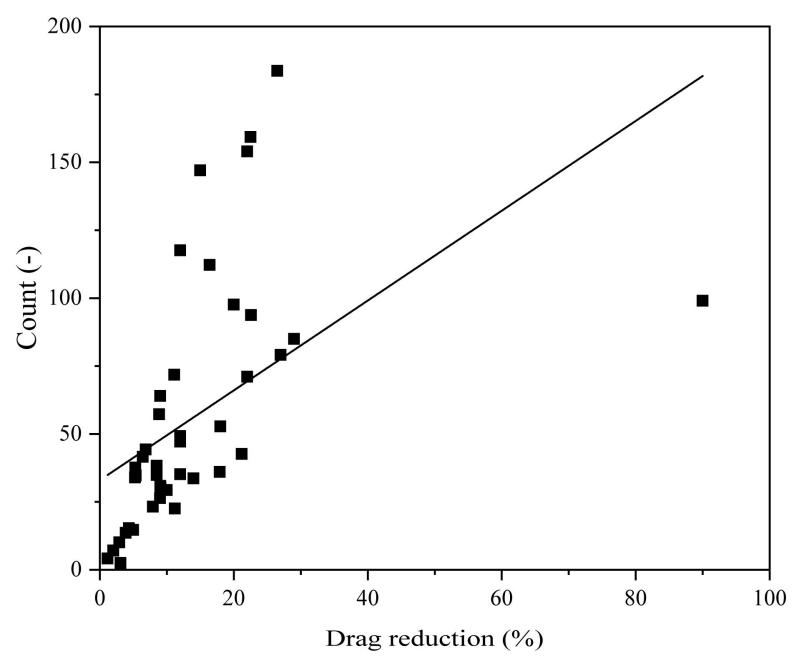

Figure 6. Connection between Count and Drag reduction (line fitted curve with $\mathrm{R}^{2}=0.26$ ).

For better comparison, both DR and Count values are presented in Figure 7a,b. Quartile ranges were different due to $C_{\text {Dinitial }}\left(\right.$ Count $\left.=10 \cdot D R C_{\text {Dinitial }}\right)$.

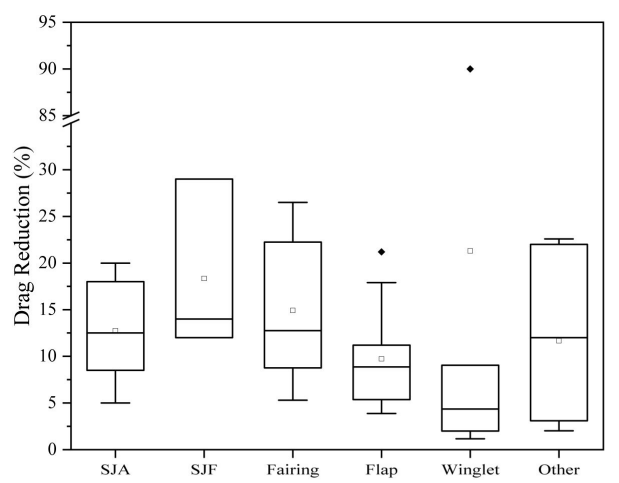

(a)

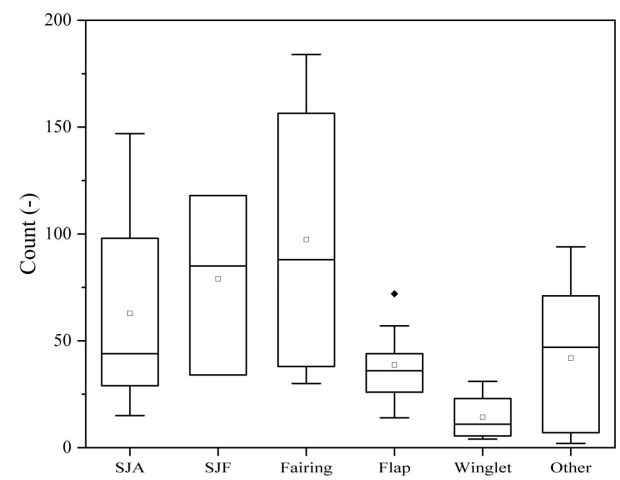

(b)

Figure 7. Reduced drag boxplot in (a) percentage and (b) in Count (line is median, $\square$ mean, $\downarrow$ peaking values).

Overall, in all 32 researches and 43 included cases, mean DR was $13.67 \% \pm 14.06 \%$. Negative DR $\left(C_{D}\right.$ increase was not observed), the lowest was $1.17 \%$ and maximum was $90 \%$. Median from these were $10 \%$. Out of the 43,21 cases had higher value than the mean value. From these, there were 7 active, 5 shape, and 9 topology cases (see Tables 1-3).

Highest DR $=90 \%$ was achieved by Gopal et al. [100] in 2012. Later, this was reproduced with a numerical simulation by Selvaraju et al. [94], which showed lower ( $\mathrm{DR}=9.04 \%)$. It has to be 
noted that the experimental measurement was done at $2.5 \mathrm{~m} \mathrm{~s}^{-1}$, which could lead to over prediction. Gopal et al. [100] also showed that this DR could be reduced to $20 \%$ at higher velocities.

Count mean value was $55.58 \pm 45$; the $\mathrm{DR}=90 \%$ was not notable since the corresponding $\mathrm{C}_{\text {Dinitial }}$ was low [100]. When Count is ranked, only 15 cases had higher than 56 with 6 shapes ( 3 in the top 3), 5 topology, and 4 cases with active methods.

For DR SJF (18.33\%) and SJA (12.75\%), active methods are favourable, since these had the highest median values from the subcategories (see Figure 7a). As for Count, Fairings (97), and SJF (79) were favourable (see Figure 7b). The Flap and Winglet subcategories had the lowest mean and median DR and Count values.

The two most favourable categories were the SJF and Fairings. One of them had larger value in Figure 7a,b. For high drag vehicle SJF, for low drag vehicle, Fairings is more advised.

Data that were presented in Figures 5-7 can be seen in a tabulated version, in Tables 1-3, divided according to the three main categories.

For active systems, the largest DR was 29\% (85 Count) and the largest Count was 147 (DR $=15 \%$ ). As previously mentioned, the maximum DR was achieved by a high flowrate at the rear slant [15], while the lowest was an active mechanism [58]. As for Count, the highest was attained with an SJA system.

From the 6 SJA method, neither DR nor Count values had connection with the St values. From St 0.1 [47] 12.1 [10], it had low and high reductions, which made it difficult to establish general connection to the actuation frequency, though it supports Kourta et al. [14]'s findings.

The active methods mostly relied on experimental measurements from the 12 presented papers, out of which 11 were using wind tunnel measurements; in addition, 7 applied PIV, and only Li et al. 2018 [58] used CFD software.

Table 1. Maximum DR by active systems.

\begin{tabular}{ccccc}
\hline Reference and Year & Method & DR & C $_{\text {Dinitial }}$ & Count \\
\hline Pastoor et al., 2008 [47] & SJA (St $=0.1)$ & $15.00 \%$ & 0.980 & 147 \\
Aubrun et al., 2011 [48] & SJF & $14.00 \%$ & 0.240 & 34 \\
Littlewood et al., 2012 [49] & SJF & $12.00 \%$ & 0.980 & 118 \\
Gilléron et al., 2013 [53] & pulse jet actuation (St = 3.6) & $20.00 \%$ & 0.488 & 98 \\
Kourta et al., 2013 [14] & SJA (St $=5.5)$ & $8.50 \%$ & 0.410 & 35 \\
Barros et al., 2016 [9] & pulse jet actuation (St =12.1) & $18.00 \%$ & 0.293 & 53 \\
Tounsi et al., 2016 [51] & SJA (St = 5.84) & $10.00 \%$ & 0.293 & 29 \\
Gao et al., 2016 [52] & SJA (St $=0.2)$ & $5.00 \%$ & 0.293 & 15 \\
Li et al., 2018 [58] & active grille shutter control mechanism & $2.91 \%$ & 0.346 & 10 \\
Zhang et al., 2018 [15] & SJF & $29.00 \%$ & 0.293 & 85 \\
Hui et al., 2019 [10] & plasma actuator (f =6.7 kHz) & $7.92 \%$ & 0.293 & 23 \\
Wang et al., 2020 [29] & wheel-vehicle interaction & $12.00 \%$ & 0.393 & 47 \\
\hline
\end{tabular}

Table 2. Maximum DR by shape modification.

\begin{tabular}{ccccc}
\hline Reference and Year & Method & DR & C $_{\text {Dinitial }}$ & Count \\
\hline Rakibul Hassan et al., 2014 [70] & rear under-body slice & $22.00 \%$ & 0.323 & 71 \\
Hwang et al., 2016 [17] & flap-type side skirts & $5.30 \%$ & 0.709 & 38 \\
Kim et al., 2017 [66] & cab fairings & $22.50 \%$ & 0.708 & 159 \\
Kim et al., 2017 [67] & gap fairings & $16.40 \%$ & 0.684 & 112 \\
Lee et al., 2017 [64] & boat tails & $9.02 \%$ & 0.709 & 64 \\
Peng et al., 2018 [68] & fairings & $8.49 \%$ & 0.451 & 38 \\
Kim et al., 2019 [69] & flap-type side skirts & $26.50 \%$ & 0.693 & 184 \\
Chowdhury et al., 2019 [22] & fairings & $22.00 \%$ & 0.700 & 154 \\
Lorite-Díez et al., 2020 [65] & curved boat tail & $9.10 \%$ & 0.329 & 30 \\
\hline
\end{tabular}


Table 3. Maximum DR by topology modification.

\begin{tabular}{ccccc}
\hline Reference and Year & Method & DR & C $_{\text {Dinitial }}$ & Count \\
\hline Aider et al., 2010 [91] & trapezoid wing & $12.00 \%$ & 0.410 & 49 \\
Gilliéron et al., 2010 [98] & front splitter plate & $27.00 \%$ & 0.293 & 79 \\
Gilliéron et al., 2010 [98] & rear splitter plate & $12.00 \%$ & 0.293 & 35 \\
Fourrié et al., 2011 [96] & rectangular flap & $9.00 \%$ & 0.293 & 26 \\
Hasan Ali et al., 2012 [92] & bump-shaped winglet & $2.00 \%$ & 0.350 & 7 \\
Gopal et al., 2012 [100] & delta winglet & $90.00 \%$ & 0.110 & 99 \\
Altaf et al., 2014 [78] & elliptical rear flap & $11.11 \%$ & 0.646 & 72 \\
Altaf et al., 2014 [78] & rectangular rear flap & $6.85 \%$ & 0.646 & 44 \\
Altaf et al., 2014 [78] & triangular rear flap & $6.43 \%$ & 0.646 & 42 \\
Altaf et al., 2014 [78] & perforated elliptical rear flap & $8.86 \%$ & 0.646 & 57 \\
Altaf et al., 2014 [78] & perforated rectangular rear flap & $5.37 \%$ & 0.646 & 35 \\
Altaf et al., 2014 [78] & perforated triangular rear flap & $5.26 \%$ & 0.646 & 34 \\
Bansal et al., 2014 [79] & spoiler & $2.02 \%$ & 0.351 & 7 \\
Bansal et al., 2014 [79] & rectangular flap & $3.87 \%$ & 0.351 & 14 \\
Bansal et al., 2014 [79] & delta winglet & $1.17 \%$ & 0.351 & 4 \\
Bansal et al., 2014 [79] & spoiler with winglet & $4.35 \%$ & 0.351 & 15 \\
Tian et al., 2017 [97] & rear flap at top & $17.90 \%$ & 0.201 & 36 \\
Tian et al., 2017 [97] & rear flap at bottom & $11.20 \%$ & 0.201 & 23 \\
Tian et al., 2017 [97] & side flap & $21.20 \%$ & 0.201 & 43 \\
Selvaraju et al., 2019 [94] & delta winglet & $9.04 \%$ & 0.341 & 31 \\
Lee et al., 2019 [19] & spoiler & $3.10 \%$ & 0.080 & 2 \\
Cihan 2019 [99] & spoiler with winglet & $22.59 \%$ & 0.415 & 94 \\
\hline
\end{tabular}

Moreover, 10 papers that discussed drag reduction by shape optimization used CFD in 5 cases; and wind tunnel measurements were presented 9 times. The reason for the larger amount of CFD applications is that, with numerically it is faster to examine different geometry, while it is crucial to have a validated model, as previously mentioned.

From Table 2, it can be seen that the most effective drag reduction was achieved when side skirt was used on a high drag vehicle. Both DR and Count $(26.50 \%$ and 184$)$ had a maximum in the work by Kim et al. [69].

Between DR or Count and $\mathrm{C}_{\text {Dinitial }}$, or year of publication, no correlations were found. The mean value was $14.91 \% \pm 8 \%(97.38 \pm 63)$. It can be attributed that the standard deviation was relatively large compared to the mean value, yet the difference between mean and median was relatively small $(12 \%)$. This main category had the highest minimum value, which shows its effectiveness of the methods.

For topology modifications, the methods had a longer list. Between 2010 and 2020, 13 relevant research papers were found that discussed DR on cars. From these papers, significant change could be seen where purely numerical evaluations were made. From the mentioned articles, only two (Hasan Ali et al. [92] and Bansal et al. [79]) compared their results with wind tunnel measurements. The rest had only validated the CFD models. It is also worth noting that RANS was used for modelling, and with one exception (Lee et al. [19]), effect was not examined with DES or LES methods. Six papers had experimental results to compare the topology modification effects. In Section 2.3.3, it was mentioned that a small wing is a VG type; it was solely applied in ref. [91]. This method was an adjustable height VG. It could have been categorized to winglet due to the height width ratio and to flap due to the surface orientation. Since it was adjustable, it could have even been added to active systems, since it can work adaptively. Flap and Winglet type DR (and Count) mean values were $9.73 \% \pm 5.44 \%$ $(38.72 \pm 16.00)$ and $21.31 \% \pm 38.52 \%(209 \pm 436)$, respectively. Winglets showed more potential over Flaps. Due to peaking values, subcategories had large standard deviations, though median values had similar for Flap and Winglet, 8.86\% (36) and 4.35\% (15), respectively. Purely spoiler application did not show notable DR (2.02\% [79] and 3.10\% [19]).

Difference between the upward $(\mathrm{DR}=15.64 \% \pm 5.68 \%$; Count $=45.17 \pm 25.87[91,96,97,99])$ and downward ( $\mathrm{DR}=7.31 \% \pm 2.27 \%$; Count $=47.33 \pm 14.64$ [78]) facing flaps, the DR value was almost $50 \%$, while in Count, it was less than 2, which leads to a conclusion that upward facing flaps are more 
beneficial. Downward facing flaps can also be categorized as a partial boat tail application method. Boat tails have $2 \%(\mathrm{DR}=9.02 \%[64]$ and $\mathrm{DR}=9.10 \%[65]$ ), more DR than downward flap in average $\mathrm{DR}=7.31 \%[78]$.

From the 32 analysed works, 20 cases attained their results with CFD and 27 cases with wind tunnel measurement. From the wind tunnel measurement, only 16 used PIV. For numerical evaluation, only two papers used different methods than RANS [17]; for turbulence modelling, $\mathrm{k}-\varepsilon$ is a highly favoured method. It is also notable that only six papers included comparison of CFD and wind tunnel measurements.

\section{Conclusions}

Quantitative analysis made for drag reduction methods, where relative, and absolute drag change was used for evaluations. Drag reduction methods were divided into three main categories: active, shape, and topology. For better comparison, these were divided into subcategories: steady flow jet, synthetic actuation flow, fairings, flaps, and winglets. An additional category was made for those that was difficult to categorise due to its uniqueness. Based on the mean value of subcategories, it was shown that steady jet flow and applications of fairings should be the most favourable drag reduction methods. Additional fairings are slightly favoured at aerodynamic vehicles over steady jet flow. Winglets and flaps are the least favoured categories. Combination of different methods should always increase the magnitude of reduction.

Based on the examined papers, it showed that synthetic jet actuation requires fine flow control, due to the manipulation of the Kelvin-Helmholtz effect. Active pulsating flow control was only viable at low velocities, while vortex generators favoured at higher velocities.

The review is limited to low-Re wind tunnel measurements and a validated version of CFD models of ground vehicles. Based on the literature review, the following research recommendations were made.

Steady flow control systems show promising results. Application on the leading should be examined to reduce corner vortices on bluff bodies.

Further vortex generator topology optimization should be made to achieve comparable reduction magnitudes to other active or shape modification methods. Low-Re PIV examination amounts should be increased for vortex generators.

As for further conclusions, connection should be made between the relative size of wake region change and drag reduction.

Finally, on-road measurements are not highly researched compared to drag measurements or drag reduction evaluations.

Funding: The research was financed by the Thematic Excellence Programme of the Ministry for Innovation and Technology in Hungary (ED_18-1-2019-0028), within the framework of the (Automotive Industry) thematic programme of the University of Debrecen.

Conflicts of Interest: The author declares no conflict of interest.

\section{References}

1. Spalart, P.R.; Strelets, M.; Travin, A. Direct numerical simulation of large-eddy-break-up devices in a boundary layer. Int. J. Heat Fluid Flow 2006, 27, 902-910. [CrossRef]

2. Taylor, H.D. Summary Report on Vortex Generators; Research Department Report No. R-05280-9; United Aircraft Corporation: East Hartford, CT, USA, 1950.

3. Chai, L.; Tassou, S.A. A Review of Airside Heat Transfer Augmentation with Vortex Generators on Heat Transfer Surface. Energies 2018, 11, 2737. [CrossRef]

4. Alexandersen, J.; Andreasen, C.S. A Review of Topology Optimisation for Fluid-Based Problems. Fluids 2020, 5, 29. [CrossRef]

5. Hucho, W.H.; Sovran, G. Aerodynamics of Road Vehicles. Annu. Rev. Fluid Mech. 1993, 25, 485-537. [CrossRef] 
6. Choi, H.; Lee, J.; Park, H. Aerodynamics of Heavy Vehicles. Annu. Rev. Fluid Mech. 2014, 46, 441-468. [CrossRef]

7. Ahmed, S.; Ramm, G.; Faltin, G. Some Salient Features of the Time-Averaged Ground Vehicle Wake; SAE Technical Papers; SAE International: Warrendale, PA, USA, 1984. [CrossRef]

8. Gil, P. Bluff Body Drag Control using Synthetic Jet. J. Appl. Fluid Mech. 2019, 12, 293-302. [CrossRef]

9. Barros, D.; Borée, J.; Noack, B.R.; Spohn, A.; Ruiz, T. Bluff body drag manipulation using pulsed jets and Coanda effect. J. Fluid Mech. 2016, 805, 422-459. [CrossRef]

10. Hui, Z.; Hu, X.; Guo, P.; Wang, Z.; Wang, J. Separation Flow Control of a Generic Ground Vehicle Using an SDBD Plasma Actuator. Energies 2019, 12, 3805. [CrossRef]

11. Götz, H. Commercial Vehicles. In Aerodynamics of Road Vehicles, 1st ed.; Hucho, W.-H., Ed.; Butterworth \& Co.: Cambridge, UK, 1987; pp. 295-354.

12. Barden, J.; Gerova, K. An on-road investigation into the conditions experienced by a heavy goods vehicle operating within the United Kingdom. Transp. Res. Part D Transp. Environ. 2016, 48, 284-297. [CrossRef]

13. Nabavi, M.; Siddiqui, M.H.K.; Dargahi, J. Experimental investigation of the formation of acoustic streaming in a rectangular enclosure using a synchronized PIV technique. Meas. Sci. Technol. 2008, 19, 65405. [CrossRef]

14. Kourta, A.; Leclerc, C. Characterization of synthetic jet actuation with application to Ahmed body wake. Sensors Actuators A Phys. 2013, 192, 13-26. [CrossRef]

15. Zhang, B.F.; Liu, K.; Zhou, Y.; To, S.; Tu, J.Y. Active drag reduction of a high-drag Ahmed body based on steady blowing. J. Fluid Mech. 2018, 856, 351-396. [CrossRef]

16. Rao, A.N.; Zhang, J.; Minelli, G.; Basara, B.; Krajnovic, S. An LES Investigation of the Near-Wake Flow Topology of a Simplified Heavy Vehicle. Flow Turbul. Combust. 2018, 102, 389-415. [CrossRef]

17. Hwang, B.G.; Lee, S.; Lee, E.J.; Kim, J.J.; Kim, M.; You, D.; Lee, S.-J. Reduction of drag in heavy vehicles with two different types of advanced side skirts. J. Wind. Eng. Ind. Aerodyn. 2016, 155, 36-46. [CrossRef]

18. Yong, Z.; Zhengqi, G.; Shuichang, L. Transient Simulation Research on Automobile Aerodynamic Lift Based on LBM Method. Mechanika 2018, 23, 845-851. [CrossRef]

19. Lee, S.W.; Kim, H.L. Numerical Study of Active Aerodynamic Control via Flow Discharge on a High-Camber Rear Spoiler of a Road Vehicle. Appl. Sci. 2019, 9, 4783. [CrossRef]

20. Weinman, K.; Fragner, M.; Deiterding, R.; Heine, D.; Fey, U.; Braenstroem, F.; Schultz, B.; Wagner, C. Assessment of the mesh refinement influence on the computed flow-fields about a model train in comparison with wind tunnel measurements. J. Wind. Eng. Ind. Aerodyn. 2018, 179, 102-117. [CrossRef]

21. Fu, C.; Uddin, M.; Robinson, A.C. Turbulence modeling effects on the CFD predictions of flow over a NASCAR Gen 6 racecar. J. Wind. Eng. Ind. Aerodyn. 2018, 176, 98-111. [CrossRef]

22. Chowdhury, H.; Juwono, R.; Zaid, M.; Islam, R.; Loganathan, B.; Alam, F. An experimental study on of the effect of various deflectors used for light trucks in Indian subcontinent. Energy Procedia 2019, 160, 34-39. [CrossRef]

23. Boyer, H.; Sigurdson, L. Flow visualization of light vehicle-trailer systems aerodynamics. J. Vis. 2014, 18, 459-468. [CrossRef]

24. McArthur, D.; Burton, D.; Thompson, M.; Sheridan, J. An experimental characterisation of the wake of a detailed heavy vehicle in cross-wind. J. Wind. Eng. Ind. Aerodyn. 2018, 175, 364-375. [CrossRef]

25. Giappino, S.; Melzi, S.; Tomasini, G. High-speed freight trains for intermodal transportation: Wind tunnel study on the aerodynamic coefficients of container wagons. J. Wind. Eng. Ind. Aerodyn. 2018, 175, 111-119. [CrossRef]

26. Pavia, G.; Passmore, M.; Varney, M.; Hodgson, G. Salient three-dimensional features of the turbulent wake of a simplified square-back vehicle. J. Fluid Mech. 2020, 888. [CrossRef]

27. Aljure, D.; Lehmkuhl, O.; Rodriguez, I.; Oliva, A. Flow and turbulent structures around simplified car models. Comput. Fluids 2014, 96, 122-135. [CrossRef]

28. Perzon, S.; Davidson, L. On transient modeling of the flow around vehicles using the Reynolds equation. In Proceedings of the ACFD 2000, Beijing, China, 17-20 October 2000; pp. 720-727. Available online: http://www.tfd.chalmers.se/ \{\}lada/postscript_files/sven_acfd_paper_2000.pdf (accessed on 7 January 2020).

29. Wang, Y.; Sicot, C.; Borée, J.; Grandemange, M. Experimental study of wheel-vehicle aerodynamic interactions. J. Wind. Eng. Ind. Aerodyn. 2020, 198, 104062. [CrossRef]

30. Pavia, G.; Passmore, M.; Varney, M. Low-frequency wake dynamics for a square-back vehicle with side trailing edge tapers. J. Wind. Eng. Ind. Aerodyn. 2019, 184, 417-435. [CrossRef] 
31. Luckhurst, S.; Varney, M.; Xia, H.; Passmore, M.; Gaylard, A. Computational investigation into the sensitivity of a simplified vehicle wake to small base geometry changes. J. Wind. Eng. Ind. Aerodyn. 2019, 185, 1-15. [CrossRef]

32. Serre, E.; Minguez, M.; Pasquetti, R.; Guilmineau, E.; Deng, G.B.; Kornhaas, M.; Schäfer, M.; Fröhlich, J.; Hinterberger, C.; Rodi, W. On simulating the turbulent flow around the Ahmed body: A French-German collaborative evaluation of LES and DES. Comput. Fluids 2013, 78, 10-23. [CrossRef]

33. Lienhart, H.; Stoots, C.; Becker, S. Flow and Turbulence Structures in the Wake of a Simplified Car Model (Ahmed Modell). In New Results in Numerical and Experimental Fluid Mechanics III; Springer: Berlin, Heidelberg, 2002; pp. 323-330. [CrossRef]

34. Wang, P.; Fröhlich, J.; Michelassi, V.; Rodi, W. Large-eddy simulation of variable-density turbulent axisymmetric jets. Int. J. Heat Fluid Flow 2008, 29, 654-664. [CrossRef]

35. Zhang, B.F.; Zhou, Y.; To, S. Unsteady flow structures around a high-drag Ahmed body. J. Fluid Mech. 2015, 777, 291-326. [CrossRef]

36. Heft, A.I.; Indinger, T.; Adams, N.A. Introduction of a New Realistic Generic Car Model for Aerodynamic Investigations; SAE Technical Paper; SAE International: Detroit, Michigan USA, 2012. [CrossRef]

37. Wieser, D.; Nayeri, C.; Paschereit, C.O. Wake Structures and Surface Patterns of the DrivAer Notchback Car Model under Side Wind Conditions. Energies 2020, 13, 320. [CrossRef]

38. Wieser, D.; Schmidt, H.-J.; Müller, S.; Strangfeld, C.; Nayeri, C.; Paschereit, C.O. Experimental Comparison of the Aerodynamic Behavior of Fastback and Notchback DrivAer Models. SAE Int. J. Passeng. Cars Mech. Syst. 2014, 7, 682-691. [CrossRef]

39. Avadiar, T.; Thompson, M.C.; Sheridan, J.; Burton, D. Characterisation of the wake of the DrivAer estate vehicle. J. Wind. Eng. Ind. Aerodyn. 2018, 177, 242-259. [CrossRef]

40. Boysen, N.; Briskorn, D.; Schwerdfeger, S. The identical-path truck platooning problem. Transp. Res. Part B Methodol. 2018, 109, 26-39. [CrossRef]

41. Jacuzzi, E.; Granlund, K. Passive flow control for drag reduction in vehicle platoons. J. Wind. Eng. Ind. Aerodyn. 2019, 189, 104-117. [CrossRef]

42. Sugimachi, T.; Fukao, T.; Suzuki, Y.; Kawashima, H. Development of Autonomous Platooning System for Heavy-Duty Trucks. In Proceedings of the 7th IFAC Symposium on Advances in Automotive Control, The International Federation of Automatic Control, Tokyo, Japan, 2013; Volume 46, pp. 52-57. [CrossRef]

43. Luo, F.; Larson, J.; Munson, T. Coordinated platooning with multiple speeds. Transp. Res. Part C Emerg. Technol. 2018, 90, 213-225. [CrossRef]

44. He, M.; Huo, S.; Hemida, H.; Bourriez, F.; Robertson, F.; Soper, D.; Sterling, M.; Baker, C. Detached eddy simulation of a closely running lorry platoon. J. Wind. Eng. Ind. Aerodyn. 2019, 193, 103956. [CrossRef]

45. Chowdhury, H.; Islam, R.; Hussein, M.; Zaid, M.; Loganathan, B.; Alam, F. Design of an energy efficient car by biomimicry of a boxfish. Energy Procedia 2019, 160, 40-44. [CrossRef]

46. Zhang, C.; Uddin, M.; Robinson, A.C.; Foster, L.; Robinson, C. Full vehicle CFD investigations on the influence of front-end configuration on radiator performance and cooling drag. Appl. Therm. Eng. 2018, 130, 1328-1340. [CrossRef]

47. Pastoor, M.; Henning, L.; Noack, B.R.; King, R.; Tadmor, G. Feedback shear layer control for bluff body drag reduction. J. Fluid Mech. 2008, 608. [CrossRef]

48. Aubrun, S.; McNally, J.; Alvi, F.; Kourta, A. Separation flow control on a generic ground vehicle using steady microjet arrays. Exp. Fluids 2011, 51, 1177-1187. [CrossRef]

49. Littlewood, R.P.; Passmore, M. Aerodynamic drag reduction of a simplified squareback vehicle using steady blowing. Exp. Fluids 2012, 53, 519-529. [CrossRef]

50. Lehugeur, B.; Gilliéron, P.; Kourta, A. Experimental investigation on longitudinal vortex control over a dihedral bluff body. Exp. Fluids 2009, 48, 33-48. [CrossRef]

51. Tounsi, N.; Mestiri, R.; Keirsbulck, L.; Oualli, H.; Hanchi, S.; Aloui, F. Experimental Study of Flow Control on Bluff Body using Piezoelectric Actuators. J. Appl. Fluid Mech. 2016, 9, 827-838. [CrossRef]

52. Gao, N.; Li, Y.Q.; Bai, H.; Wu, C.J. Effects of Synthetic jets on a D-Shaped Cylinder wake at a Subcritical Reynolds Number. Flow Turbul. Combust. 2016, 97, 729-742. [CrossRef]

53. Gilliéron, P.; Kourta, A. Aerodynamic drag control by pulsed jets on simplified car geometry. Exp. Fluids 2013, 54. [CrossRef] 
54. Brackston, R.; Wynn, A.; Morrison, J. Modelling and feedback control of vortex shedding for drag reduction of a turbulent bluff body wake. Int. J. Heat Fluid Flow 2018, 71, 127-136. [CrossRef]

55. Eulalie, Y.; Fournier, E.; Gilotte, P.; Holst, D.; Johnson, S.; Nayeri, C.; Schütz, T.; Wieser, D. Active flow control analysis at the rear of an SUV. Int. J. Numer. Methods Heat Fluid Flow 2018, 28. [CrossRef]

56. Leclerc, C.; Levallois, E.; Kourta, A.; Gilliéron, P. Aerodynamic Drag Reduction by Synthetic Jet: A 2D Numerical Study around a Simplified Car. In Proceedings of the 3rd AIAA Flow Control Conference, San Francisco, CA, USA, 5-8 June 2006.

57. Bruneau, C.-H.; Creusé, E.; Gilliéron, P.; Mortazavi, I. Effect of the vortex dynamics on the drag coefficient of a square back Ahmed body: Application to the flow control. Eur. J. Mech. B Fluids 2014, 45, 1-11. [CrossRef]

58. Li, J.; Deng, Y.D.; Wang, Y.; Su, C.; Liu, X. CFD-Based research on control strategy of the opening of Active Grille Shutter on automobile. Case Stud. Therm. Eng. 2018, 12, 390-395. [CrossRef]

59. Dhanasekar, J.; Sengottuvel, P.; Palanikumar, K. Implementation of Effective Fuel Saving Methodology for Turbines using Air Drag in Vehicles. Mater. Today Proc. 2019, 16, 421-429. [CrossRef]

60. Qi, L.; Wu, X.; Zeng, X.; Feng, Y.; Pan, H.; Zhang, Z.; Yuan, Y. An electro-mechanical braking energy recovery system based on coil springs for energy saving applications in electric vehicles. Energy 2020, 200, 117472. [CrossRef]

61. Huri, D.; Mankovits, T. Automotive rubber part design using machine learning. IOP Conf. Series Mater. Sci. Eng. 2019, 659, 012022. [CrossRef]

62. Huri, D.; Mankovits, T. Comparison of the material models in rubber finite element analysis. IOP Conf. Series Mater. Sci. Eng. 2018, 393, 012018. [CrossRef]

63. Gunpinar, E.; Coskun, U.C.; Ozsipahi, M.; Gunpinar, S. A Generative Design and Drag Coefficient Prediction System for Sedan Car Side Silhouettes based on Computational Fluid Dynamics. Comput. Des. 2019, 111, 65-79. [CrossRef]

64. Lee, E.J. Drag reduction of a heavy vehicle using a modified boat tail with lower inclined air deflector. J. Vis. 2017, 14, 319-752. [CrossRef]

65. Lorite-Díez, M.; Jiménez-González, J.I.; Pastur, L.; Cadot, O.; Martínez-Bazán, C. Drag reduction on a three-dimensional blunt body with different rear cavities under cross-wind conditions. J. Wind. Eng. Ind. Aerodyn. 2020, 200, 104145. [CrossRef]

66. Kim, J.J.; Hong, J.; Lee, S.-J. Bio-inspired cab-roof fairing of heavy vehicles for enhancing drag reduction and driving stability. Int. J. Mech. Sci. 2017, 132, 868-879. [CrossRef]

67. Kim, J.J.; Kim, J.; Lee, S.-J. Substantial drag reduction of a tractor-trailer vehicle using gap fairings. J. Wind. Eng. Ind. Aerodyn. 2017, 171, 93-100. [CrossRef]

68. Peng, J.; Wang, T.; Yang, T.; Sun, X.; Li, G. Research on the Aerodynamic Characteristics of Tractor-Trailers with a Parametric Cab Design. Appl. Sci. 2018, 8, 791. [CrossRef]

69. Kim, J.J.; Kim, J.; Hann, T.; Kim, D.; Roh, H.S.; Lee, S.-J. Considerable drag reduction and fuel saving of a tractor-trailer using additive aerodynamic devices. J. Wind. Eng. Ind. Aerodyn. 2019, 191, 54-62. [CrossRef]

70. Hassan, S.R.; Islam, T.; Ali, M.; Islam, Q. Numerical Study on Aerodynamic Drag Reduction of Racing Cars. Procedia Eng. 2014, 90, 308-313. [CrossRef]

71. Vignesh, S.; Gangad, V.S.; Jishnu, V.; Maheswarreddy, K.A.; Mukkamala, Y.S. Windscreen angle and Hood inclination optimization for drag reduction in cars. Procedia Manuf. 2019, 30, 685-692. [CrossRef]

72. He, P.; Mader, C.; Martins, J.R.R.A.; Maki, K.J. An aerodynamic design optimization framework using a discrete adjoint approach with OpenFOAM. Comput. Fluids 2018, 168, 285-303. [CrossRef]

73. Hassaan, M.; Badlani, D.; Nazarinia, M. On the effect of boat-tails on a simplified heavy vehicle geometry under crosswinds. J. Wind. Eng. Ind. Aerodyn. 2018, 183, 172-186. [CrossRef]

74. Holt, J.; Garry, K.; Velikov, S. A wind tunnel investigation into the effects of roof curvature on the aerodynamic drag experienced by a light goods vehicle. Int. J. Veh. Des. 2015, 67, 45. [CrossRef]

75. Jadhav, C.R.; Chorage, R.P. Modification in commercial bus model to overcome aerodynamic drag effect by using CFD analysis. Results Eng. 2020, 6, 100091. [CrossRef]

76. Liu, F.; Ji, X.; Hu, G.; Gao, J. A Novel Shape-Adjustable Surface and Its Applications in Car Design. Appl. Sci. 2019, 9, 2339. [CrossRef]

77. Salati, L.; Schito, P.; Cheli, F. Strategies to reduce the risk of side wind induced accident on heavy truck. J. Fluids Struct. 2019, 88, 331-351. [CrossRef] 
78. Altaf, A.; Omar, A.A.; Asrar, W. Passive drag reduction of square back road vehicles. J. Wind. Eng. Ind. Aerodyn. 2014, 134, 30-43. [CrossRef]

79. Bansal, R.; Sharma, R.B. Drag Reduction of Passenger Car Using Add-On Devices. J. Aerodyn. 2014, 2014, 678518. [CrossRef]

80. Li, X.-K.; Liu, W.; Zhang, T.-J.; Wang, P.-M.; Wang, X. Analysis of the Effect of Vortex Generator Spacing on Boundary Layer Flow Separation Control. Appl. Sci. 2019, 9, 5495. [CrossRef]

81. Li, X.; Yang, K.; Wang, X. Experimental and Numerical Analysis of the Effect of Vortex Generator Height on Vortex Characteristics and Airfoil Aerodynamic Performance. Energies 2019, 12, 959. [CrossRef]

82. Li, X.-K.; Liu, W.; Zhang, T.-J.; Wang, P.-M.; Wang, X. Experimental and Numerical Analysis of the Effect of Vortex Generator Installation Angle on Flow Separation Control. Energies 2019, 12, 4583. [CrossRef]

83. Gutierrez-Amo, R.; Fernandez-Gamiz, U.; Errasti, I.; Zulueta, E. Computational Modelling of Three Different Sub-Boundary Layer Vortex Generators on a Flat Plate. Energies 2018, 11, 3107. [CrossRef]

84. Errasti, I.; Fernandez-Gamiz, U.; Martínez-Filgueira, P.; Blanco, J.M. Source Term Modelling of Vane-Type Vortex Generators under Adverse Pressure Gradient in OpenFOAM. Energies 2019, 12, 605. [CrossRef]

85. Godard, G.; Foucaut, J.; Stanislas, M. Control of a decelerating boundary layer. Part 2: Optimization of slotted jets vortex generators. Aerosp. Sci. Technol. 2006, 10, 394-400. [CrossRef]

86. Godard, G.; Stanislas, M. Control of a decelerating boundary layer. Part 3: Optimization of round jets vortex generators. Aerosp. Sci. Technol. 2006, 10, 455-464. [CrossRef]

87. Hansen, M.O.L.; Charalampous, A.; Foucaut, J.-M.; Cuvier, C.; Velte, C.M. Validation of a Model for Estimating the Strength of a Vortex Created from the Bound Circulation of a Vortex Generator. Energies 2019, 12, 2781. [CrossRef]

88. Lo, K.H.; Kontis, K. Flow characteristics over a tractor-trailer model with and without vane-type vortex generator installed. J. Wind. Eng. Ind. Aerodyn. 2016, 159, 110-122. [CrossRef]

89. Shivam, S.S.; Guleria, A.; Mukkamala, Y.S. Aerodynamic Drag Reduction of a Notchback Car Geometry by Delaying Flow Separation using Vortex Generators. Int. J. Eng. Res. 2015, V4, 521-524. [CrossRef]

90. Ibarra-Udaeta, I.; Errasti, I.; Fernandez-Gamiz, U.; Zulueta, E.; Sancho, J. Computational Characterization of a Rectangular Vortex Generator on a Flat Plate for Different Vane Heights and Angles. Appl. Sci. 2019, $9,995$. [CrossRef]

91. Aider, J.-L.; Beaudoin, J.-F.; Wesfreid, J.E. Drag and lift reduction of a 3D bluff-body using active vortex generators. Exp. Fluids 2009, 48, 771-789. [CrossRef]

92. Ali, M.H.; Mashud, M.; al Bari, A.; Islam, M.M. Aerodynamic drag reduction of a car by vortex generation. Int. J. Mech. Eng. 2012, 2, 2277-7059.

93. Sardana, H.; Singh, M. Reduction of Drag of SUV Similar to Tata Sumo Using Vortex Generator. J. Theor. Appl. Mech. 2018, 48, 19-30. [CrossRef]

94. Selvaraju, P.N.; Parammasivam, K.M. Empirical and Numerical Analysis of Aerodynamic Drag on a Typical SUV Car Model at Different Locations of Vortex Generator. J. Appl. Fluid Mech. 2019, 12, 1487-1496. [CrossRef]

95. Sen, W.; Rahman, K.A.; Tanim, I.K. Experimental and CFD Analysis on Car with Several Types of Vortex Generators. In Proceedings of the International Conference on Mechanical Engineering and Renewable Energy 2019, Chittagong, Bangladesh, 11-13 December 2019.

96. Fourrié, G.; Keirsbulck, L.; Labraga, L.; Gilliéron, P. Bluff-body drag reduction using a deflector. Exp. Fluids 2010, 50, 385-395. [CrossRef]

97. Tian, J.; Zhang, Y.; Zhu, H.; Xiao, H. Aerodynamic drag reduction and flow control of Ahmed body with flaps. Adv. Mech. Eng. 2017, 9, 1-17. [CrossRef]

98. Gilliéron, P.; Kourta, A. Aerodynamic drag reduction by vertical splitter plates. Exp. Fluids 2009, 48, 1-16. [CrossRef]

99. Cihan, B. Numerical Drag Reduction of a Ground Vehicle by NACA2415 Airfoil Structured Vortex Generator and Spoiler. Int. J. Automot. Technol. 2019, 20, 943-948. [CrossRef]

100. Gopal, P.; Senthilkumar, T.; Rameshkumar, C. Aerodynamic drag reduction in a passenger vehicle using vortex generator with varying yaw angles. ARPN J. Eng. Appl. Sci. 2012, 7, 1180-1186.

(C) 2020 by the author. Licensee MDPI, Basel, Switzerland. This article is an open access article distributed under the terms and conditions of the Creative Commons Attribution (CC BY) license (http://creativecommons.org/licenses/by/4.0/). 